\title{
QoE: Quality of Experience: A Conceptual Essay
}

\author{
Regis Cabral \\ Digital Media Laboratory \\ Applied Physics and Electronics \\ Umeå University \\ SE-901 87 Umeå universitet Sweden \\ regis.cabral@tfe.umu.se, \\ http://www.medialab.tfe.umu.se/
}

\begin{abstract}
The ICT industry and services are on the verge of substituting quality of service and utility functions with quality of experience, QoE. While intuitive, QoE, has eluded the research community. QoE takes into account what the user is experiencing with new products and services. Once this information is collected, it becomes an input in the development of the new product or new service. But how does one measure directly quality of experience? In this conceptual paper, I discuss from an ICT perspective, the utility function and quality of service, QoS. I also present how active interested the industry is in QoE. I concluded with some key points that may serve as a guideline in the process of constructing the QoE function.
\end{abstract}

\section{Introduction}

In recent years, the ICT industry and related services have highlighted that concepts such as quality of service and even utility functions, while useful, have failed in contributing to product and service development from the perspective of the consumer. One can say that quality of service has even failed in capturing the needs of the consumer. The concept of quality of experience, QoE, is emerging as an alternative. The concept seems to be easy to understand intuitively. Nevertheless, QoE has eluded the research community. One takes into account what the user is experiencing with new products and services. Once this information is collected, it becomes an input in the development of the new product or new service. Other fields, beyond ICT, like the health sector or the food sector, have a long history of using qualitative approaches to deal with similar issues. But quality of experience, while

Please use the following format when citing this chapter:

Cabral, R., 2007, in IFIP International Federation for Information Processing, Volume 252, Integration and Innovation Orient to L-Society Volume 2, eds. Wang, W., (Boston: Springer), pp. 193-199. 
similar to consumer satisfaction, it is not the same. Consumer satisfaction has been used has a proxy for QoE and surveys and questionnaires have been common approaches. But how does one measure directly quality of experience? In this conceptual discussion, I present some (but not all) concepts that are relevant to the ICT sectors, such as utility function and quality of service. Then I attempt a definition of QoE and enter suggestions about how to measure it directly.

\section{Relevant concepts $[1,2,3,4,5]$}

\subsection{The utility function}

It may come as a surprise to many that the concept of utility has not been defined $100 \%$ unequivocally. Nevertheless, the utility functions is assumed to be properly and well defined. Engineers use it as a standard instrument to compare technologies. But is it well defined? If we open standard works or encyclopedias in economics, it is clear that the concept of utility emerged in history as a way to measure a user satisfaction with products or services. So a society would aim at maximizing its utility. That is, society should strive at making all, (and if not all the greatest number,) of its members happy. An important name in utilitarianism was John Stuart Mill.

The difficulties at measuring something as "irrational" as happiness, forced economists to reconsider utility as a behavioral measure. So a behavior became rational when it maximizes utility - what ever that might be. Utility became a curve representing how a society or an individual consumed, or accepted, goods and services, to a certain satisfaction level. How to best achieve an efficient use of these goods and services so as to maximize this utility function became a social and individual objective in economics.

It is very relevant for a discussion of quality of experience to consider that there are two types of utility, cardinal and ordinal. The former relates to magnitudes while the later to ranking. In both cases one is referring to a society or a consumer's preferences. It is clear that ordinal utility represents a behavioral choice but does not tells us what the user is experiencing and neither which product is better or worst. Cardinal utility functions have, for all practical purposes, disappeared from neoclassical economics. What has happened is that consumer purchase preferences have became, in practice, proxies for utility functions. It is assumed that what consumers choose has been chosen rationally to maximize their utility. Mathematical formulations have followed from this. Or alternatively, mathematical formulations have been interpreted this way. Utility functions are (quite often linear and wellbehaved) ranking of user's possible choices from a consumer set. It is assumed that what the consumer chooses is what the consumer prefers, no matter what the consumer experiences. In the expected utility models, consumers and society are expected to avoid risk in their choices. The key names were von Neumann and Morgenstern.

Difficulties with utility, particularly when monetary and price issues emerged, required economists to consider marginal utility. Utility reduces to that which is used 
at the margin. But different consumers will attribute different marginal utilities to the same product or the same service. Theories of marginal utility may confront difficulties not only because of this but also because of the attempts to associate this marginal change to quantifiable entities or measures. Quantification may be possible if the marginal utility changes can be associated to changes from one economic state to another. But again this does not tells us much about the quality of the experience the consumer may be having. And this is so, even in microeconomics where consumers have to maximize their utility with their choice of money allocation, given several goods, services and savings to choose from. It is straightforward to show that in most cases the problem has several solutions. In addition, consumers may have a behavior described as satisficing, which means just choosing what is good enough even if it is not the best - the bounded rationality behavior. Utility is also a function of knowledge, information, energy, time and other factors. This means that the utility function may be describing a choice but not the maximization of the quality of experience of the consumer.

\subsection{Quality of Service - QoS}

While ICT engineers use utility functions to develop their products and services., there emerged a need to offer to consumers the best possible service, given resources, infrastructures and technology. QoS is used widely in the ICT sector with this purpose. In contrast to the utility function, quality of service is very clearly defined, including in several international standards. For instance in telephony, QoS is "a set of quality requirements on the collective behavior of one or more objects", according to ITU standard X902 [2]. Given a network that combines several technologies, including IP-routed networks, QoS will give us a measure of the network's capability to provide the best possible service given a selected network traffic. The QoS function must take into account factors such as bandwidth, latency and loss characteristics. The QoS function also allows for service providers to measure the extent to which providing one flow of information through the network does not impair other flows. Without a measure of QoS it is not possible to provide such services as WAN and IOS.

There is another important contrast to the utility functions. QoS are actually control mechanisms. Users, application softwares and data flows have priorities in the networks and it is QoS that determines who goes first, given the actual limited physical qualities of the network. With QoS a traffic control that guarantees traffic without quality impair is possible. With this in mind it is clear that QoS is not the same as high performance. We can not measure QoS directly with low latency or low bit error probability for instance, although these can be used as proxies or indicators of QoS.

QoS can be affected by many factors, for instance networks delays, out of order deliveries, dropped packets and errors in general. Providers make an extreme effort at not loosing packages from origin to destination.

Some current network services would be impossible without QoS, for instance streaming multimedia, IPTV, and asynchronous transfer mode (ATM) with one of its 
key applications VOIP. QoS statistics show that networks that provide QoS can be as much as for times more reliable than a network without QoS.

It is also clear that if there is substantial capacity in the bandwidth than one can operate without QoS. It is here that one can see the difference between QoS and quality of experience, QoE. The user or consumer may have a good quality of experience even when QoS is not in place. ICT providers can not evaluate QoE from QoE and vice-versa. But, they actually need to know QoE to determine their customer relations.

\section{Quality of Experience - QoE - What is it?}

Quality of experience can not be considered a "new" concept. In several business sectors, there has been serious attempts to take into account the customer's perspective. Product developers, particular in the consumer goods sectors, have constantly asked themselves about what needs to change in a product in order to meet the needs of the consumer. But QoE is also a reaction to mass production society. But it has been very difficult to measure it objectively. The use of questionnaires and interviews has proved problematic, particularly for the fast growing and fast changing ICT sector. Here I will not considere the parallel and similar issue that has been under consideration in the medical sector. Since health is directly related to the patient quality of experience with the medical service, medical providers have been looking into this issue also.

In the ICT sector is has long been considered that QoE is subjective. It is our contention that it is possible to quantify or at least measure QoE. That is, it is possible to take the user into account in the services provided, even if dependent on the user's previous experiences. QoS, particularly when measured by the Mean Opinion Score (MOS) has been used as a proxy for QoE, but it is limited because it requires a highly controlled environment.

Since the great contributions of Harrison White [7], networks have been well established as a research tool. In the case of innovation this has been facilitated by the acceptance and implementation of national and regional systems of innovation. Such understanding of the dynamics of networks gives us a point of departure to consider the very important issue of quality of experience. QoE is of fundamental interest for video mobile service, as has been highlighted by Nokia and Ericsson literature. QoE is expected to replace both utility functions and quality of service. Quality of experience, in contrast to quality of service, QoE, takes into account how a user, particularly in the video mobile networks, assesses and evaluates a service/product innovation in relation to existing services/products. Basically, QoE will measure if an innovation will reduce or increase the transaction costs (and not only monetary costs) from the perspective of the user's experience. QoE is an emerging but very difficult concept and has baffled large corporations like Nokia and Ericsson. The literature is so far internal or limited, with exception of the health sector, from which ideas can be imported. QoE is of fundamental importance for the positioning of Finland and Nokia in the European and in the global market [8]. So far, has neither Ericsson nor Nokia been able to successful address the issue of how to 
measure QoE. There are indications that Samsung may be on the right track, although mobile video providers may enter higher demands on technology producers. This has recently been highlighted by the work of M.A Sasse, UCL [9], as well as by the seminars promoted by the German telecom interests. In Sweden, the dissertation of Jiong Sun on Streaming Video has also reinforced the need to advance on this front [10]. An important alternative is to develop intelligent video displays [11].

Over all, QoE will become more important than quality of service and for management, and management theory/economics, and probably more important as the utility function. Moreover a functional $\mathrm{QoE}$ may give an extra innovative edge to companies in Sweden's and Finland's science parks and incubators [12, 13, 14]

Certainly a number of companies are capitalizing on the possibilities of measuring QoE. This includes for instance LCC International, which has announcement for "wireless turn-key services, ... and end-user 'Quality of Experience' solution". LCC suggests that it is measuring the "actual consumer experience". LCC is highlighting that it is tracking, among other things, consumers' download options and thus identifying preferences. Their preliminary results indicate that fewer than $20 \%$ of customers are satisfied with their experience with mobile content services [15]. Another company is Nominum but their product description indicates a high quality in QoS. This would improve reduce problems for customers QoE [16].

\section{Can we measure QoE?}

The industrial interest in QoE and its measuring is demonstrated by the large number of entries in Google - over 250000 relevant entries by 15 May 2007. The academic work in the economics and theory of QoE has been restricted to the economics of experience. But a search for a metric is most relevant [17]. So the belief is that QoE can be measure and that it can be done quantitatively. Efforts such as the Quality of Experience Initative, led by Zandan and supported by LCC, Freever, mBlox, Motricity, Musiwave, and Vodafone reinforces the perception here presented about the importance of QoE [18]. Ericsson is also moving in this direction, as indicated in its "User Service Performance white Paper of February 2007 [19].

What is it that we know so far?

1. QoE is not the same as QoS

2. The two may occur at the same time, but one does not necessarily leads to the other

3. QoS is not sufficient for the development of products and services that take into account the customer's experience

4. Utility function is not sufficient for the development of products and services that take into account the customer's experience

5. QoS is not the same as the utility function

6. QoE is not the same as the utility function

7. But it is very likely that there is a relationship between utility and QoE 
8. QoE is a function of behavioral variables that may be possible to measure quantitatively.

9. Some of these measures may be physiometrical and psychometrical.

10. In case of mobile telephony this may be possible directly through the mobile phone in participating populations

11. Utility is one of the variables of the QoE function

\section{References}

1. M. Blaug, The Methodology of Economics or How Economists Explain (Cambridge Univ. Press, Cambridge, 2nd ed, 1992).

2. T. Eggertsson, Economic Behavior and Institutions (Cambridge University Press, Cambridge, 1999).

3. F. Fisher, The Identification Problem in Econometrics (McGraw-Hill, New York, 1966)

4 .U. Mäki, Fact and Fiction in Economics: Models, Realism and Social Construction (Cambridge University Press, Cambridge, 2002).

5 .S. S. Stevens, Measurements, Psychophysics and Utility, edited by C. W. Churchman and R. Philburn, Measurement: Definitions and Theories (New York: John Wiley, New York, 1959), pp. 18-63.

6. ITU (February 2003); www.itu.int/itudoc/itu-t/com17/activity/cat004_ww9.doc.

7. J. Moody, review of Harrison White's Markets from Networks: Socioeconomic, Models of Production Social Forces, 81 (2), 663-664 (2002).

8 .NOKIA, (October 2004), Quality of Experience (QoE) of Mobile Services: Can It Be Measured and Improved? http://whitepapers.silicon.com/0,39024759,60104519p9000457q,00.htm

9 . Angela Sasse (May 2007);

http://www.cs.ucl.ac.uk/staff/a.sasse/angelasasse.html.

10 J. Sun, Football on Mobile Phones. Algorithms, Architectures and quality of Experience in Streaming Video (PhD Dissertation, Department of Applied Physics and Electronics, Umeå University, 2006).

11 . C. Kim, J. Ko, I. Ahn, M. Usman, J.H. Kwon, J. Park, Y. H. Joo, and Y. J. $\mathrm{Oh}$, Intelligent Video Display to Raise Quality of Experience on Mobile Devices, Applications of Digital Image Processing XXIX. Proceedings of the SPIE 6312, pp. 63120N (2006).

12. A.-V. Anttiroiko, Editorial: Global Competition of High-Tech Centres, International Journal of Technology Management 28 (3/4/576), pp. 289-323 (2004).

13. R. Cabral, The Cabral-Dahab Science Park Management Paradigm: An Introduction, International Journal of Technology Management, 16, pp. 721-725 (1998).

14. R. Cabral, The Cabral-Dahab Science Park Management Paradigm applied to the case of Kista, Sweden, International Journal of Technology Management 28 (3-6), pp. 419-443 (2004).

15. LCC (February 13, 2007) LCC Solution Measures 'Quality of Experience'; http://www.mobilemarketingmagazine.co.uk/2007/02/lcc_solution_me.html. 
16.Daily News (2007), Nominum Enhances Products For Wireless Quality Of Experience, Daily News; http://newsblaze.com/story/20070206160437youn.np/topstory.html

17.EMA (March 22, 2006), Adopting the ultimate service metric: A checklist for an effective Quality of Experience solution, Enterprise Management Associates (EMA), http://www.compuware.com/default.asp.

18. MEF, London (May 2007); http://www.m-e-forg/index.php?id=43.

Ericsson, (February 2007) Ericsson User Service Performance, February 2007, White paper 284 23-3106 UEN Rev A;

http://www.ericsson.com/technology/whitepapers/3106_user_service_performance_A.pdf. 